\title{
Copper(II), cobalt(II), nickel(II) and zinc(II) complexes of Schiff base derived from benzil-2,4-dinitrophenylhydrazone with aniline
}

\author{
N RAMAN*, S RAVICHANDRAN and C THANGARAJA \\ Department of Chemistry, VHNSN College, Virudhunagar 626 001, India \\ e-mail: drn_raman@yahoo.co.in
}

MS received 13 August 2003; revised 1 June 2004

\begin{abstract}
New Schiff base chelates of $\mathrm{Cu}(\mathrm{II}), \mathrm{Co}(\mathrm{II}), \mathrm{Ni}(\mathrm{II})$ and $\mathrm{Zn}$ (II) derived from benzil-2,4-dinitrophenylhydrazone with aniline have been synthesised. Microanalytical data, molar conductance, and magnetic susceptibility values have been obtained, and IR, ${ }^{1} \mathrm{H}$ NMR, ${ }^{13} \mathrm{C} N M R$, UV-Vis, CV and EPR spectral studies have been carried out to suggest tentative structures for the complexes.
\end{abstract}

Keywords. Benzil-2,4-dinitrophenylhydrazone; Schiff base complexes; EPR; cyclic voltammetry.

\section{Introduction}

Metal complexes of Schiff bases have played a central role in the development of coordination chemistry. From the survey of existing literature, it appears that benzil monophenylhyrazone and its related compounds have been extensively used as biologically active complexing agents and analytical reagents. ${ }^{1-6}$ Keeping the above facts in mind and in continuation of our research work ${ }^{7-9}$ on transition metal (II) complexes with Schiff bases, in the present paper we report the synthesis and characterization of $\mathrm{Cu}(\mathrm{II}), \mathrm{Co}(\mathrm{II}), \mathrm{Ni}(\mathrm{II})$ and $\mathrm{Zn}$ (II) complexes of Schiff base derived from the condensation of benzil-2,4-dinitrophenylhydrazone with aniline. The proposed structure of the complexes is shown in chart 1.

\section{Experimental}

All the chemicals used were of AnalaR grade. Aniline was distilled prior to use. The solvents were dried and distilled before use according to standard procedures. The supporting electrolyte, $\mathrm{NaClO}_{4}$ used in the voltammetric experiment was purchased from Sigma. IR spectra were recorded in $\mathrm{KBr}$ medium on a Perkin-Elmer 783 spectrophotometer. The ${ }^{1} \mathrm{H}$ and

${ }^{13} \mathrm{C}$ NMR spectra were recorded at Madurai Kamaraj University, on a Brucker instrument using TMS as internal standard. The UV-Vis spectra of all the

$\overline{\text { *For correspondence }}$ complexes were recorded in acetone on a Shimadzu UV-1601 spectrophotometer. Microanalytical data were performed at the Regional Sophisticated Instrumentation Centre, Central Drug Research Institute, Lucknow. Magnetic susceptibility measurements of the complexes in the solid state were determined by Gouy balance using $\mathrm{CuSO}_{4}$ as the calibrant. Molar conductances of the complexes were measured in acetone at room temperature using systronic conductivity bridge type 305 . Electrochemical measurements were carried out in Electrochemical Analyser model BAS-50 voltammograph. The three-electrode cell contained a reference $\mathrm{Ag} / \mathrm{AgCl}$ electrode, $\mathrm{Pt}$ wire auxillary electrode and glassy carbon

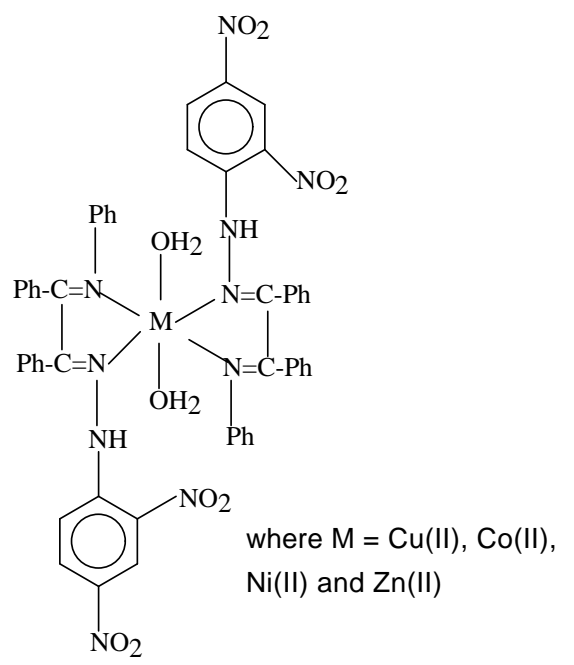

Chart 1. 
working electrode. ESR spectra of the copper complex were recorded on a Varian E112 X-band spectrometer at the Regional Sophisticated Instrumentation Centre, Indian Institute of Technology, Mumbai using tetracyanoethylene (TCNE) as the internal standard.

\subsection{Synthesis of Schiff base}

The Schiff base was synthesised by the condensation of benzil-2,4-dinitrophenylhydrazone and aniline (1:1 molar ratio), dissolved in ethanol. The resulting reaction mixture was refluxed for $\approx 1 \mathrm{~h}$. The yellow solid precipitate of Schiff base obtained was filtered, washed with distilled water dried, recrystallised from ethanol and finally preserved in a desiccator. Yield: $58 \%$ (m.p.: $138^{\circ} \mathrm{C}$ ).

\subsection{Synthesis of complexes}

An ethanolic $(10 \mathrm{ml})$ solution of Schiff base $(10 \mathrm{mM})$ was mixed with metal (II) chloride $(5 \mathrm{mM})$ in ethanol $(10 \mathrm{ml})$ solution keeping ligand-metal ratio $2: 1$ followed by few drops of acetic acid $(\mathrm{pH}=6)$. The mixture was then refluxed for $\approx 1 \mathrm{~h}$ on a water bath till the complex precipitated out. Precipitate obtained was dried over $\mathrm{KOH}$ pellets. The solid product obtained was filtered, washed with distilled water and dried in vacuo.

\section{Results and discussion}

The analytical data along with some physical properties of the complexes are summarised in table 1. The ligand $\mathrm{L}$, on interaction with $\mathrm{Cu}(\mathrm{II}), \mathrm{Co}(\mathrm{II})$, $\mathrm{Ni}(\mathrm{II})$ and $\mathrm{Zn}$ (II) chlorides, yields complexes corresponding to the general formula $\left[\mathrm{ML}_{2}\left(\mathrm{H}_{2} \mathrm{O}\right)_{2}\right]$. The analytical data show that the metal to ligand ratio is $1: 2$. They are soluble in common organic solvents. The low molar conductance values of the complexes reveal their non-electrolytic nature. ${ }^{10}$

\subsection{IR spectra}

In order to study the binding mode of Schiff base to metal in the complexes, IR spectrum of the free ligand was compared with the spectra of the metal complexes. Benzil-2,4-dinitrophenylhydrazone shows its characteristics absorption bands in the 3100,1645 , 1620 and $920 \mathrm{~cm}^{-1}$ regions, assignable to $\mathrm{N}-\mathrm{H}, \mathrm{C}=\mathrm{O}$, $\mathrm{C}=\mathrm{N}$ and $\mathrm{N}-\mathrm{N}$ vibrations respectively. Infrared spe- ctra of the Schiff base ligand, benzil-2,4-dinitrophenylhydrazone with aniline has the important absorption bands in the $3100,1605-1630$ and $920 \mathrm{~cm}^{-1}$ regions assignable ${ }^{11}$ to $\mathrm{N}-\mathrm{H}, \mathrm{C}=\mathrm{N}$ and $\mathrm{N}-\mathrm{N}$ respectively. The band(s) at $1605-1630 \mathrm{~cm}^{-1}$ due to the azomethine group of the Schiff base underwent a shift to lower frequency $\left(1580-1590 \mathrm{~cm}^{-1}\right)$ after complexation, indicating the coordination of azomethine nitrogen to metal atom and this can be explained by the donation of electrons from nitrogen to the empty $d$-orbitals of the metal atom. In the spectra of all complexes, the broad band at $\approx 3400 \mathrm{~cm}^{-1}$, together with new band at $\approx 890 \mathrm{~cm}^{-1}$ indicating the presence of coordinated water. The nature of metalligand bonding is confirmed by the newly formed band at $\approx 440 \mathrm{~cm}^{-1}$ in the spectra of the complexes which is tentatively assigned to $\mathrm{M}-\mathrm{N}$ vibration.

\section{$3.2{ }^{1} \mathrm{H}$ and ${ }^{13} \mathrm{C}$ NMR spectra}

The ${ }^{1} \mathrm{H}-\mathrm{NMR}$ spectrum of the Schiff base ligand exhibits a multiplet signal at 7.3-7.8 $\delta(\mathrm{m}, \mathrm{Ar}-\mathrm{H})$ and $10 \cdot 1 \delta(s, \mathrm{~N}-\mathrm{H})$. In $\mathrm{Zn}(\mathrm{II})$ complex, the $\mathrm{N}-\mathrm{H}$ proton is shifted slightly downfield at $10 \cdot 3 \delta$ which reveals the bonding of the azomethine nitrogen to $\mathrm{Zn}$ (II) ion. The ${ }^{13} \mathrm{C}$-NMR spectra of $\mathrm{Zn}$ (II) complex was recorded by employing TMS as internal reference and $\mathrm{CDCl}_{3}$ as solvent at ambient temperature. The number of signals of sharp peaks represent the number of carbons of the compound which are chemically non-equivalent. The spectra exhibit the azomethine, $\mathrm{C}=\mathrm{N}$ carbon at $178 \mathrm{ppm}$. The chemical shift of aromatic carbons appear at 138, 128, 126 and $121 \mathrm{ppm}$.

\subsection{Electronic absorption spectra}

The electronic absorption spectra are often very helpful in the evaluation of results furnished by other methods of structural investigation. The electronic spectral measurements were used for assigning the stereochemistries of metal ions in the complexes based on the positions and number of $d-d$ transition peaks. The electronic absorption spectra of the Schiff base and its $\mathrm{Cu}$ (II), Co(II), Ni(II) and $\mathrm{Zn}$ (II) complexes were recorded at room temperature using acetone as solvent. Only one broad band is observed at $16,638 \mathrm{~cm}^{-1}$ in the electronic spectrum of the $\mathrm{Cu}$ (II) complex assigned to ${ }^{2} E_{g} \rightarrow{ }^{2} T_{2 g}$ transition which is in conformity with octahedral geometry ${ }^{12}$. Though three transitions are expected in this case, they are very close in energy and often appear in the 
Table 1. Physical characteristics and analytical data of the complexes.

\begin{tabular}{|c|c|c|c|c|c|c|c|}
\hline \multirow[b]{2}{*}{ Compound } & \multicolumn{4}{|c|}{ Analysis, found (calcd) (\%) } & \multirow[b]{2}{*}{ Yield $(\%)$} & \multirow[b]{2}{*}{$\mu_{\text {eff }}(B M)$} & \multirow{2}{*}{$\begin{array}{c}\lambda \mathrm{m} \\
\left(\mathrm{mho} \mathrm{cm}^{-2} \mathrm{~mol}^{-1}\right)\end{array}$} \\
\hline & M & $\mathrm{C}$ & $\mathrm{H}$ & $\mathrm{N}$ & & & \\
\hline Ligand & - & $\begin{array}{c}66 \cdot 4 \\
(67 \cdot 1)\end{array}$ & $\begin{array}{c}3 \cdot 7 \\
(4 \cdot 1)\end{array}$ & $\begin{array}{c}14.9 \\
(15 \cdot 1)\end{array}$ & 60 & - & - \\
\hline$\left[\mathrm{CuL}_{2}\left(\mathrm{H}_{2} \mathrm{O}\right)_{2}\right]$ & $\begin{array}{c}5 \cdot 0 \\
(6 \cdot 2)\end{array}$ & $\begin{array}{c}58 \cdot 9 \\
(61 \cdot 5)\end{array}$ & $\begin{array}{c}3 \cdot 8 \\
(4 \cdot 1)\end{array}$ & $\begin{array}{c}13 \cdot 1 \\
(13 \cdot 6)\end{array}$ & 56 & $1 \cdot 9$ & $12 \cdot 6$ \\
\hline$\left[\mathrm{CoL}_{2}\left(\mathrm{H}_{2} \mathrm{O}\right)_{2}\right]$ & $\begin{array}{c}5.9 \\
(5 \cdot 8)\end{array}$ & $\begin{array}{c}59 \cdot 4 \\
(61 \cdot 8)\end{array}$ & $\begin{array}{c}4 \cdot 0 \\
(4 \cdot 1)\end{array}$ & $\begin{array}{c}13 \cdot 2 \\
(13 \cdot 6)\end{array}$ & 59 & $4 \cdot 8$ & $11 \cdot 5$ \\
\hline$\left[\mathrm{NiL}_{2}\left(\mathrm{H}_{2} \mathrm{O}\right)_{2}\right]$ & $\begin{array}{c}5 \cdot 7 \\
(5 \cdot 8)\end{array}$ & $\begin{array}{c}60 \cdot 7 \\
(61 \cdot 9)\end{array}$ & $\begin{array}{c}3 \cdot 7 \\
(4 \cdot 1)\end{array}$ & $\begin{array}{c}12 \cdot 4 \\
(13 \cdot 7)\end{array}$ & 55 & $2 \cdot 8$ & $11 \cdot 2$ \\
\hline$\left[\mathrm{ZnL}_{2}\left(\mathrm{H}_{2} \mathrm{O}\right)_{2}\right]$ & $\begin{array}{c}5 \cdot 4 \\
(6 \cdot 3)\end{array}$ & $\begin{array}{c}60 \cdot 3 \\
(62 \cdot 8)\end{array}$ & $\begin{array}{c}3 \cdot 4 \\
(4 \cdot 2)\end{array}$ & $\begin{array}{c}12.9 \\
(13 \cdot 6)\end{array}$ & 58 & - & $10 \cdot 7$ \\
\hline
\end{tabular}

$\mathrm{L}=$ Schiff base ligand

form of one broad band envelope. The electronic spectra of Co(II) complex showed two spin-allowed transitions at 17856 and $21734 \mathrm{~cm}^{-1}$ assignable to ${ }^{4} T_{1 g}(F) \rightarrow{ }^{4} A_{2 g}(F)$ and ${ }^{4} T_{1 g}(F) \rightarrow{ }^{4} T_{1 g}(P)$ transitions respectively, are in conformity with octahedral arrangements for $\mathrm{Co}(\mathrm{II})$ ion. ${ }^{13}$ The appearance of a band at $19240 \mathrm{~cm}^{-1}$ due to ${ }^{3} A_{2 g}(F) \rightarrow{ }^{3} T_{1 g}(P)$ transition favours an octahedral geometry ${ }^{14}$ for the $\mathrm{Ni}(\mathrm{II})$ complex. The absence of any band below $10,000 \mathrm{~cm}^{-1}$ eliminates the possibility of a tetrahedral environment in this complex. The electronic spectrum of the $\mathrm{Zn}$ (II) complex shows an absorption band at $23,455 \mathrm{~cm}^{-1}$ attributed to the LMCT transition, which is compatible with this complex having an octahedral structure. ${ }^{15,16}$

\subsection{Magnetic susceptibility measurements}

The magnetic moment value of $\mathrm{Cu}$ (II) complex is $1.90 \mathrm{BM}$ which suggests a distorted octahedral geometry ${ }^{17,18}$ around the metal ion. The magnetic moment of $\mathrm{Co}$ (II) complex is $4.81 \mathrm{BM}$ which suggests the high spin six-coordinated octahedral arrangement ${ }^{19,20}$ of ligand molecules around the metal ion. The Ni(II) complex has magnetic moment value of $2.8 \mathrm{BM}$ indicating a spin-free octahedral ${ }^{21,22}$ configuration. The $\mathrm{Zn}(\mathrm{II})$ complex is found to be diamagnetic as expected for $d^{10}$ configuration.

\subsection{ESR spectra}

The ESR spectra of copper complex provide information of importance in studying the metal ion environment. The X-band ESR spectra of the $\mathrm{Cu}(\mathrm{II})$ complex, recorded in DMSO at liquid nitrogen temperature and at room temperature $(300 \mathrm{~K})$, are shown in figures 1 and 2 . The spectrum of the copper complex at room temperature shows one intense absorption band in the high field and is isotropic due to the tumbling motion of the molecules. However, this complex in the frozen state shows four well resolved peaks with low field region. The copper complex exhibits the $g_{\|}$value of $2 \cdot 31$ and $g_{\perp}$ value of $2 \cdot 16$. These values indicate that the ground state ${ }^{23}$ of $\mathrm{Cu}$ (II) is predominantly $d_{x^{2}-y^{2}}$. The spin-orbit coupling constant, $\lambda$ value $\left(-486 \mathrm{~cm}^{-1}\right)$ calculated using the relations, $g_{\mathrm{av}}=1 / 3\left[g_{\|}+2 g_{\perp}\right]$ and $g_{\mathrm{av}}=2(1-2 \lambda /$ $10 D q)$, is less than the free $\mathrm{Cu}$ (II) ion $\left(-832 \mathrm{~cm}^{-1}\right)$ which also supports covalent character ${ }^{24}$ of $\mathrm{M}-\mathrm{L}$ bond in the complex. The $G$ values of 3.82 indicates negligible exchange interaction of $\mathrm{Cu}-\mathrm{Cu}$ in the complex. The covalency parameter $\alpha^{2}$ is calculated $\left(\alpha^{2}=0 \cdot 82\right)$ using the following equation:

$$
\begin{aligned}
\alpha_{\mathrm{Cu}}^{2}= & -\left(A_{\|} / 0 \cdot 036\right)+\left(g_{\|}-2 \cdot 0023\right) \\
& +3 / 7\left(g_{\perp}-2 \cdot 0023\right)+0 \cdot 04
\end{aligned}
$$

If the value of $\alpha^{2}=0 \cdot 5$, it indicates complete covalent bonding, while the value of $\alpha^{2}=1.0$ suggests complete ionic bonding. The observed value of $\alpha^{2}$ $(0 \cdot 82)$ of the complex is less than unity, which indicates that the complex has some covalent character in the ligand environment. ${ }^{25}$

\subsection{Cyclic voltammetric study}

The cyclic voltammogram of $\mathrm{Cu}$ (II) complex $(0.01 \mathrm{M})$ in $\mathrm{MeCN}(1.0$ to $-1.2 \mathrm{~V}$ potential range) 
shows a well-defined redox process corresponding to the formation of the $\mathrm{Cu}(\mathrm{II}) / \mathrm{Cu}(\mathrm{III})$ couple at $E p_{a}=0.22 \mathrm{~V}$ and the associated cathodic peak at $E p_{c}=0.18 \mathrm{~V}$. This couple is found to be reversible with $\Delta E p \approx 0.04 \mathrm{~V}$ and the ratio of anodic to cathodic peak currents $\left(I p_{c} I I p_{a}=1\right)$ corresponding to a simple one-electron process. ${ }^{26}$ The complex also shows a quasi-reversible peak in the negative region, characteristic of the $\mathrm{Cu}(\mathrm{II}) \rightarrow \mathrm{Cu}(\mathrm{I})$ couple at $E p_{c}=$ $-0.66 \mathrm{~V}$, with associated anodic peak at $E p_{a}=$ $-0.47 \mathrm{~V}$ for $\mathrm{Cu}(\mathrm{I}) \rightarrow \mathrm{Cu}$ (II) oxidation.

The cyclic voltammogram of $\mathrm{Zn}$ (II) complex $(0.01 \mathrm{M})$ in $\mathrm{MeCN}$ solution in the absence of molecular oxygen at room temperature in 1.0 to $-1.0 \mathrm{~V}$ potential range at scan rate $50 \mathrm{mVs}^{-1}$ indicating quasi-reversible one-electron process. A noteworthy feature has been observed in the cyclic voltammogram of $\mathrm{Zn}$ (II) complex. During the forward scan it shows two cathodic reduction peaks, one at $+0.45 \mathrm{~V}$

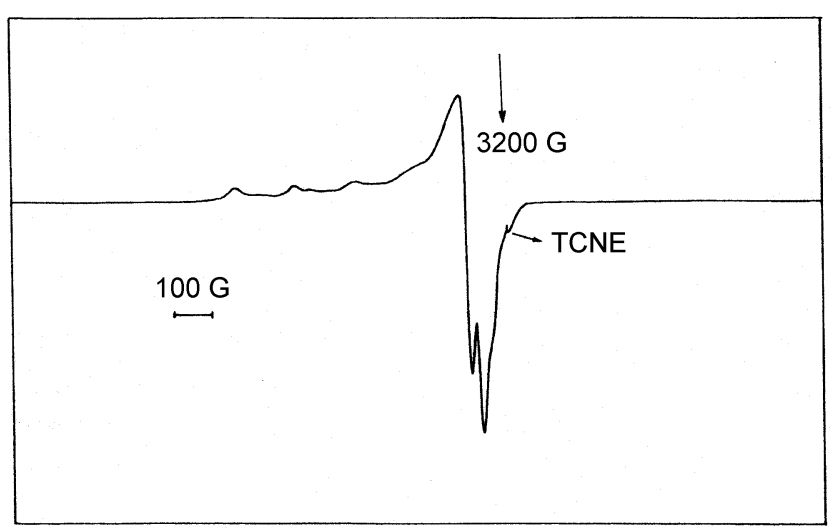

Figure 1. ESR spectra of $\mathrm{Cu}(\mathrm{II})$ complex at $77 \mathrm{~K}$ in DMSO solution.

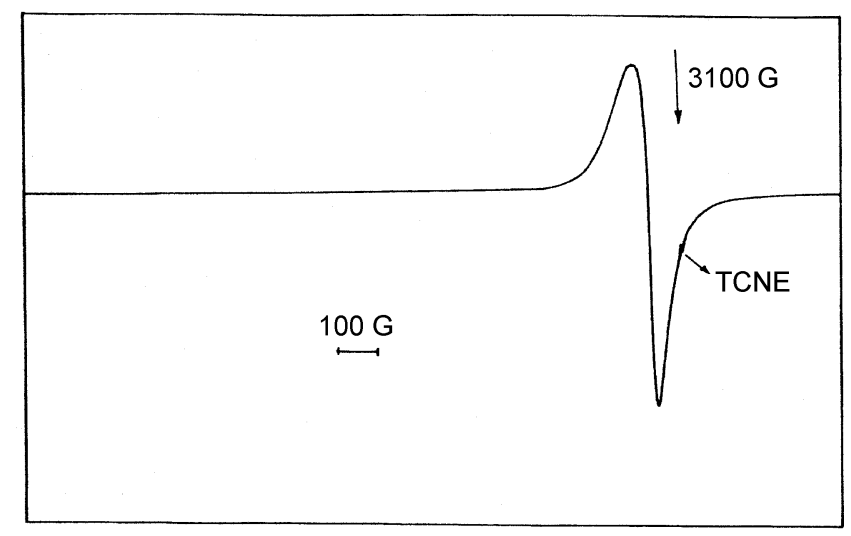

Figure 2. ESR spectra of $\mathrm{Cu}(\mathrm{II})$ complex at $300 \mathrm{~K}$ in DMSO solution. and another at $-0 \cdot 61 \mathrm{~V}$ which are attributed to reduction of $\mathrm{Zn}(\mathrm{II}) \rightarrow \mathrm{Zn}(\mathrm{I})$ and $\mathrm{Zn}(\mathrm{I}) \rightarrow \mathrm{Zn}(0)$ respectively. During the reverse scan it shows two anodic oxidation peaks, one at $-0.26 \mathrm{~V}$ and another at $+0.62 \mathrm{~V}$ which are attributed to oxidation of $\mathrm{Zn}(0) \rightarrow$ $\mathrm{Zn}(\mathrm{I})$ and $\mathrm{Zn}(\mathrm{I}) \rightarrow \mathrm{Zn}(\mathrm{II})$ respectively.

\section{Conclusions}

In this paper coordination chemistry of a Schiff base ligand, obtained from the reaction of benzil-2,4-dinitrophenylhydrazone and aniline, is described. $\mathrm{Cu}(\mathrm{II})$, $\mathrm{Co}(\mathrm{II}), \mathrm{Ni}(\mathrm{II})$ and $\mathrm{Zn}$ (II) complexes have been synthesized using the above Schiff base ligand and characterized on the basis of analytical, magnetic and spectral data. The Schiff base coordinates through its azomethine nitrogens to the metal ion and acts as a neutral bidentate ligand. All the complexes exhibit octahedral geometry.

\section{Acknowledgements}

We thank the Regional Sophisticated Instrumentation Centre, Central Drug Research Institute, Lucknow and Regional Sophisticated Instrumentation Centre, Indian Institute of Technology, Mumbai for use of instrumentation facilities. SR and CT thank the Tamilnadu Government, Chennai for financial support.

\section{References}

1. Orget L E and Dunit J D 1957 Nature (London) 179 462

2. Ito K and Ito J 1958 Aust. J. Chem. 2406

3. Goodgame D M L and Cotton F A $1961 \mathrm{~J}$. Am. Chem. Soc. 834161

4. Singh A K and Sharma U N 2002 Asian J. Chem. 14 1221

5. Sacconi L and Ciampolini M 1964 J. Chem. Soc. 276

6. Idcher A D 1963 J. Phys. Chem. 671214

7. Raman N, Selvan A and Shunmugasundaram A 1997 Asian J. Chem. 9183

8. Raman N, Kulandaisamy A, Thangaraja C and Jeyasubramanian K 2003 Transition Met. Chem. 2829

9. Raman N, Ravichandran S and Kulandaisamy A 2002 Asian J. Chem. 141261

10. Geary W J 1971 Coord. Chem. Rev. 781

11. Silverstein R M, Bassler G C and Movril T C 1981 Spectroscopic identification of organic compounds 4th edn (New York: Wiley)

12. Dunn T M 1960 The visible and ultraviolet spectra of complex compounds in modern coordination chemistry (New York: Interscience) 
13. Krishna C H, Mahapatra C M and Dush K C 1977 J. Inorg. Nucl. Chem. 391253

14. Kasim A N M, Venkappayya D and Prabhu G V 1999 J. Indian Chem. Soc. 7667

15. Chohan Z H and Parvez H H 1993 Synth. React. Inorg. Met.-Org. Chem. 231061

16. Sekerci $\mathrm{M}$ and Tas E 2000 Heteroatom Chem. 11 254

17. Figgis B N and Lewis J 1960 Modern coordination chemistry (New York: Wiley Interscience)

18. Sabastiyan A and Venkappayya D 1990 J. Indian Chem. Soc. 67584

19. Konig E 1971 Structure and bonding (Berlin: Springer Verlag) p. 175
20. Rana A K and Shah J R 1981 Indian J. Chem. A20 142

21. Cotton F A and Wilkinson G 1962 Advanced inorganic chemistry (New York: Wiley Interscience)

22. Figgis B N 1976 An introduction to ligand fields (New Delhi: Wiley Eastern)

23. Shirin Z and Mukherjee R M 1992 Polyhedron 11 2625

24. Hathway B J and Billing D E 1961 Coord. Chem. Rev. 5143

25. Kevelson D and Niedman R J 1961 Chem. Phys. 35 149

26. Shirin Z and Mukherjee R M 1992 Polyhedron 11 2625 